\title{
Medievalista
}

Online

16 | 2014

Número 16

\section{O amor pela forma no Cancioneiro Geral de Garcia de Resende}

Tese apresentada ao Programa de Pós-Graduação em Literatura Portuguesa, do Departamento de Letras Clássicas e Vernáculas da Faculdade de Filosofia, Letras e Ciências Humanas da Universidade de São Paulo, Brasil, para obtenção do título de Doutor em Letras (Literatura Portuguesa), sob orientação da $\operatorname{Prof}^{a}{ }^{\mathrm{a}} \mathrm{Dr}^{\mathrm{a}}$ Lênia Márcia de Medeiros Mongelli, em 25 de fevereiro de 2011.

\section{Geraldo Augusto Fernandes}

\section{(Q) OpenEdition}

\section{Edição electrónica}

URL: http://journals.openedition.org/medievalista/1553

DOI: $10.4000 /$ medievalista.1553

ISSN: 1646-740X

Editora

Instituto de Estudos Medievais - FCSH-UNL

\section{Refêrencia eletrónica}

Geraldo Augusto Fernandes, «O amor pela forma no Cancioneiro Geral de Garcia de Resende », Medievalista [Online], 16 | 2014, posto online no dia 01 dezembro 2014, consultado o 23 setembro 2020. URL : http://journals.openedition.org/medievalista/1553 ; DOI : https://doi.org/10.4000/ medievalista. 1553

Este documento foi criado de forma automática no dia 23 setembro 2020.

\section{(c) (7) \&}

Mediavalista está licenciado com uma Licença Creative Commons - Atribuição-NãoComercial 4.0 Internacional. 


\section{$\mathrm{O}$ amor pela forma no Cancioneiro Geral de Garcia de Resende}

Tese apresentada ao Programa de Pós-Graduação em Literatura Portuguesa, do Departamento de Letras Clássicas e Vernáculas da Faculdade de Filosofia, Letras e Ciências Humanas da Universidade de São Paulo, Brasil, para obtenção do título de Doutor em Letras (Literatura Portuguesa), sob orientação da Prof ${ }^{a} \operatorname{Dr}^{\mathrm{a}}$ Lênia Márcia de Medeiros Mongelli, em 25 de fevereiro de 2011.

\section{Geraldo Augusto Fernandes}

\section{NOTA DO EDITOR}

Data do texto: 16 de Março de 2014

1 Para Pierre Le Gentil, o amor pela forma cultivado pelos poetas medievais da Península Ibérica, principalmente os de fins de Quatrocentos e início de Quinhentos, iria se transformar em uma arte no Renascimento. Para o estudioso francês, a partir da Renascença, o formalismo será uma disciplina elegante, em que o poeta deixará transparecer sua individualidade poética. Também quanto à forma, Andrée Crabbé Rocha, em Aspectos do Cancioneiro Geral, comenta que "é a técnica exterior que se torna cada vez mais exigente, à medida que as regras do jogo vão aumentando", para, mais à frente, dizer que os poetas do Cancioneiro Geral "trabalham a sua forma, procurando dar-lhe a maior perfeição possível. Isto pode dar-se em detrimento da beleza e da poesia, é certo, pois se trata dum esforço do intelecto mais do que da sensibilidade, mas contribui largamente para dotar os poetas imediatamente posteriores dum instrumento já posto à prova".

2 Os vários artifícios presentes no Cancioneiro - e em toda produção Peninsular da época -, tais como "a engenhosa construção da arte mayor, gêneros em forma fixa, o villancico e a cantiga, o "estribote"', constituem, para Pierre Le Gentil, elementos de renovação poética "que não se encontra em outro lugar" (que não no Cancioneiro de Resende). 
Tendo por base essas afirmações, a proposta deste estudo foi a de sistematizar esse "amor pela forma" dos poetas palacianos, cujas composições foram compiladas por Garcia de Resende em seu Cancioneiro Geral, publicado em 1516, que reúne poemas desde 1450 até à data de sua publicação.

Estudiosos como Le Gentil, Crabbé Rocha e Jole Ruggieri afirmam que a poesia desenvolvida pelos poetas palacianos prenuncia estilos literários futuros, mais pela sua estrutura que pelo tema. Os vários artifícios presentes no Cancioneiro - e em toda produção peninsular da época - constituem, para o estudioso francês, elementos de renovação poética. É no Cancioneiro Geral, por exemplo, que se retoma um tema que se tornará clássico: o das visões infernais, alegação à passagem da descida aos Ínferos retratada na Divina Comédia de Dante. Na compilação de Resende, percebe-se também que os poetas estavam atentos às mudanças por que passava o Portugal dos Descobrimentos. Lisboa tornara-se uma metrópole habitada tanto por europeus ávidos pelos resultados da expansão marítima, como genoveses e florentinos, quanto por um turbilhão de escravos africanos. No poema "COUDEL-MOOR POR BREVE DE ŨA MOURISCA RATORTA QUE MANDOU FAZER A SENHORA PRINCEZA, QUANDO ESPOSOU”, de Fernão da Silveira, por exemplo, o poeta reproduz com fidelidade a fala de um negro, principalmente quanto aos verbos não conjugados, no infinitivo. Mistura decassílabos com hendecassílabos, versos de arte maior, e rimas masculinas com femininas, de natureza e disposição várias, como compete aos poetas cancioneiris de então. Mas a questão social não se revela somente na língua que era enriquecida pelos Descobrimentos - ela se revela também nas relações e nos sentimentos de temor ante um mundo em desconcerto, tema que se tornará recorrente em muitos dos poemas quinhentistas portugueses.

4 Para exortar um sentimento, valem-se os poetas do Cancioneiro de Resende, com frequência, de figuras e formas que buscam fugir a qualquer sensaboria. É claro que tudo em excesso provoca o contrário num leitor atual, mas que serviam de deleite aos apreciadores da gaia ciência da época. No processo do "Cuidar e Sospirar", primam os participantes no exercício da retórica, valendo-se do conceptismo e do cultismo, mostrando agudeza e lavor na lapidação de suas intervenções. $O$ artifício da epizeuxe, por exemplo, de que se servem para enfatizar uma ideia a ser defendida, é próprio da retórica, de que o processo jurídico-poético é exemplo cabal. Se só a temática - a defesa de sentimentos de amor enunciada num feito processual - é novidosa, apuraram os poetas participantes da tenção em fazer com que a forma sobressaísse ao fundo. Para isso, evocaram quaisquer artes que pudessem favorecer-lhes o exercício de poetar.

Muito cultivado na Península, no final do século XV, o "pé quebrado" serviu de artifício aos poetas, que o colocavam na posição que lhes aprouvesse. Ele ora aparece no mote, para enfatizar um sentimento, ora para desqualificar um oponente ou mesmo para destacar uma personalidade do Paço. 0 recurso, ainda, poderá aparecer duas vezes no mote, ou ainda, agora mais ousado, é começar uma ajuda com o "pé quebrado" e estender a cantiga para onze versos na glosa, quando o usual são versos de oito a dez. Um exemplo é a cantiga de Fernão da Silveira, intitulada "DE DOM GOTERRE AOS GIBÕOES DE FERNAM DA SILVEIRA E DOM PEDRO DA SILVA, QUE FEZERAM DE BORCADO COM MEAS MANGAS E COLAR DE GRAAM", que leva o número 590, inserido no Volume III do Cancioneiro Geral de Garcia de Resende.

Pôde-se perceber, nessa curta seleta de exemplos focados na forma, alguns traços próprios da produção poética do Quatrocentos português, considerados inovadores por 
muitos estudiosos. Na compilação, se persistiam ainda temas da tradição peninsular, aparecem também temas e formas que, de certa maneira, retratavam o período de transição da Idade Média para o Renascimento. É assim que, como justificativa para a pesquisa, o trabalho com as formas poemáticas poderá contribuir para melhor entendimento da poética engendrada pelos poetas palacianos - e, por extensão, a mentalidade deles e dos frequentadores do Paço português de Quatrocentos/ Quinhentos. A essas formas, juntam-se temas que caracterizam justamente a transição.

O objeto deste estudo, então, foi analisar/sistematizar a forma composicional dos poemas desenvolvidos pelos poetas palacianos no fim do século XV e início do XVI. Apesar de "reeditarem" temas recorrentes do período medieval - pois ainda se encontrava a sociedade destes dois séculos naquele espaço de tempo que estudiosos classificam como Idade Média -, o que se releva do compêndio de Garcia de Resende é a estrutura dos poemas. Desse modo, não se dissociará da investigação - e nem poderia ser de outro modo - o conjunto forma/conteúdo. E para embelezar essas formas, os poetas mostrarão sua agudeza no emprego dos muitos recursos retóricos, fazendo da sua poesia um rico arsenal de possibilidades expressivas.

Tendo em vista as várias opiniões quanto à forma poemática desenvolvida no Quatrocentos e no Quinhentos peninsulares, uma questão, pelo menos, avulta: teriam os poetas palacianos, cujas poesias foram compiladas por Garcia de Resende, à maneira que o faziam os poetas castelhanos dos cancioneiros de Baena, de Hernando del Castillo, Juan del Encina, Marquês de Santillana, Imperial e outros da época, apenas adotado uma nova forma poemática - ou imitado/emulado - para fugir à sensaboria ou para reavivar a poesia trovadoresca, mas, agora, de modo diferenciado? Ao se estudarem essas formas poéticas, seria possível perceber uma "poética implícita", uma vez que a explícita inexiste no Portugal de 1400 e 1500? A investigação é necessária, pois poderia contribuir para a lacuna existente quanto aos parâmetros estruturais que determinariam as poéticas medievais inexistentes no lado ocidental da Península Ibérica. Em Portugal dos séculos XV e XVI, não se produziu uma poética, como a que realizaram os provençais - as Leys d'Amors - ou como a Arte de Trobar da poesia trovadoresca galego-portuguesa, para citar apenas duas. Pelo menos, não há registro de uma produção de tal documento. Dessa forma, a resposta àqueles questionamentos poderia ajudar no melhor entendimento do processo composicional dos poetas portugueses do período delimitado para a investigação.

9 Através dessas reflexões, procuro demonstrar em minha Tese que a estrutura composicional adotada pelos poetas portugueses do Quatrocentos/Quinhentos não se restringiu à imitação do modo de compor a que se aplicaram seus vizinhos castelhanos; ainda, que esta estrutura foi deliberada e buscou as raízes eruditas na Antiguidade Clássica $^{1}$, na poesia provençal e na poesia produzida pelos trovadores galegoportugueses, tendo sido renovada essencialmente porque os novos tempos assim o exigiam. Deve-se levar em conta, também o que afirmam estudiosos: o Humanismo teria começado no século XIV, protagonizado por Dante, Petrarca e Boccaccio, que já se valiam das obras da Antiguidade Clássica como marca das preocupações humanistas² ${ }^{2}$ A primazia dos estudos e de obras representativas humanísticas dar-se-á em meados do século XVI. Contudo, o Humanismo seiscentista começa a fixar suas bases com os poetas palacianos, ao se analisar um número expressivo de poemas recorrentes à época de ouro da literatura e filosofia - a Antiguidade Clássica ${ }^{3}$. Nessa recorrência, valeram-se os poetas de forma composicional relida dos clássicos e, quanto aos temas, dedicaram-se à 
emulação dos pensamentos de Dante, Petrarca e Boccaccio, além de poetas e filósofos clássicos, tais como Horácio e Virgílio, e até da Alta Idade Média, principalmente seus contemporâneos castelhanos, como Macias, Baena, Rodríguez del Padrón e Santillana, para citar os mais representativos.

10 Entretanto, por ser um momento de mudanças, não se restringem as formas e temas à releitura da tradição - esforçam-se os poetas por cantar seu sentimento de desconfiança e desilusão quanto ao novo mundo que começa a aflorar em Lisboa; daí que novos temas são cantados em versos, retratando um mundo em desconcerto. Cantam ainda com insistência, é verdade, o amor, tema tão caro à medievalidade, mas esse amor dos novos tempos terá uma faceta mais realista e mais sincera, como se poderá observar nos exemplos analisados neste estudo.

11 Para se entender as formas de que se serviram os poetas palacianos foi necessário sistematizar e estudar, primeiramente as formas estróficas do Cancioneiro Geral; além destas, compilar e estudar, também, os artifícios retóricos e o sistema rítmico, rimático e métrico de que se serviram esses poetas. Para isso, separando cada forma e juntandoas pelas suas semelhanças, dividiu-se o Cancioneiro em seis grupos. Essa sistematização e estudo dos componentes básicos da poesia foram necessários para se entender a poética implícita da compilação de Resende, uma vez que, como já dito, não existe um documento indicativo de uma arte de trovar quinhentista, à luz daqueles produzidos por muitos dos poetas castelhanos contemporâneos aos portugueses.

12 Para poder entender esta arte, o estudo foi dividido em três partes; no Capítulo I relatam-se as diferenças teóricas entre "gênero" e "forma" e cada uma das seis formas básicas do Cancioneiro resendiano - a balada, a esparsa, a trova, o vilancete e a cantiga, exceto os poemas de formas mistas; para cada uma delas, foi dada sua definição, sua origem e aplicação nos poemas do compêndio. No Capítulo II, estudam-se as origens e as características de cada um dos quatro subgrupos de poemas de formas mistas que compõem o cancioneiro - a cantiga, a trova, o vilancete, a esparsa e a balada, seguidos cada um de outra ou outras formas, vinculados a uma mesma temática. Como se poderá constatar neste estudo, a característica básica desses poemas é ser iniciado por uma forma que se distingue das outras que lhe seguem - por exemplo, o poeta inicia uma composição pela cantiga, e a esta se seguem trovas e/ou um ou mais vilancetes. Esse modo de composição é original e foi uma das grandes inovações dos poetas de $1400 \mathrm{e}$ 1500 , castelhanos ou portugueses. No Capítulo III, estudam-se os variados recursos retóricos de que se serviram os poetas palacianos. A Retórica, que na Antiguidade estava estritamente ligada à oratória, se bem que muito usada pelos poetas clássicos, passa a ser, junto com a rima, o ritmo e a métrica, parte essencial da elocução poética. Os tropos e as figuras serão mais um dos ornamentos a embelezar esta poética, e esses recursos foram muito pouco estudados nos poemas que compõem o cancioneiro de Resende. Para estudo desses artifícios, vali-me primordialmente da Institutio oratoria de Quintiliano, sem, contudo, não deixar de recorrer a muitos outros, tais como Heinrich Lausberg e Juan Casas Rigall, para citar apenas dois.

13 Em minha Tese, procuro acentuar a importância que os poetas palacianos deram à forma. Apenas como exemplo, cito o caso da balada; a maioria dos críticos toma o termo pelo seu lado melódico, podendo ele valer tanto para a trova quanto para a cantiga. No entanto, ao dividir o cancioneiro em seis grupos de formas, pude constatar que a balada, constitui-se de várias estrofes, muitas das vezes isofórmicas, seguidas de um "cabo" com um número menor de versos. A cantiga, por sua vez, mostra-se inversa a 
este esquema - apresenta um mote com número de versos menor que as glosas. Do mesmo esquema, vale-se o vilancete. As trovas não levam um mote estrófico, mas podem levar um "cabo", cujo número de versos será o mesmo das estrofes que lhe antecedem, daí não poderem ser classificadas como "baladas"; no entanto, a engenhosidade dos poetas palacianos instiga-os a mesclarem seus versos aos versos de outros poetas conhecidos ou anônimos, dando uma face mista ao seu poema. Também nas esparsas, monostróficas, por isso não comportam nem mote nem "cabo", o desenvolvimento do tema poderá vir por glosa de versos alheios. A tudo isso, deve-se adicionar o elemento que mais caracteriza o cancioneiro de Resende: a irregularidade. Le Gentil já havia observado isso e acredita ser esta peculiaridade a grande marca da compilação e, mais que tudo, sua grande riqueza.

14 Ainda como procedimento de análise, algumas observações. Para cada forma, foi escolhido um poema - em alguns casos mais de um, como o da esparsa e o da cantiga representativo para melhor entender sua estrutura e tema. Quanto aos recursos retóricos, o estudo ficou centrado nos poemas de formas mistas, uma vez que os considero representativos do culto pela forma dos poetas palacianos - eles, sem dúvida, representam cada uma das diferentes formas cultivadas pelos trovadores do Quatrocentos/Quinhentos português. Apesar de característicos da poesia, a rima, o ritmo e a métrica não serão estudados em profundidade, uma vez que o foco serão as formas como moldes e a retórica como ornamento. No entanto, nos poemas-base de cada grupo, aqueles elementos são ressaltados e observa-se como eles se relacionam com o tema proposto pelo poeta.

15 A este estudo está incluído um Apêndice, em que se elencam - através de tabelas - as características principais dos poemas do Cancioneiro de Resende: estrofes, versos, motes, métrica, gênero, língua, pés quebrados, além de uma coluna reservada para comentário breve de alguma peculiaridade de cada poema.

A Tese completa pode ser acessada online no seguinte endereço: http:// www.teses.usp.br/teses/disponiveis/8/8150/tde-15092011-130549/. A defesa deu-se em 25 de fevereiro de 2011, na Universidade de São Paulo, São Paulo, Brasil.

\section{BIBLIOGRAFIA}

ANTUNES, Maria Helena Marques - “A argumentação no Cuidar e Sospirar”. in FRADEJAS RUEDA, José Manuel et alii (eds.) - Actas del XIII Congreso Internacional de la Asociación Hispánica de Literatura Medieval (Valladolid, 15 a 19 de septiembre de 2010). In memoriam Alan Deyermond. Valladolid: Ayuntamiento de Valladolid y Universidad de Valladolid, 2010, ISBN 978-84-693-8468-8D, pp. 353-362.

ANTUNES, Maria Helena Marques - "As cores do Cancioneiro Geral”. in CARRETO, Carlos F. Clamote; DIAS, Isabel Barros (eds.) - Cores. Actas do VII Colóquio da Secção Portuguesa da Associação Hispânica de Literatura Medieval. Lisboa: Universidade Aberta, 2010, ISBN 978-972-674-702-4, pp. 237-246. 
CAMÕES, Luís de - Os Lusíadas. Comentados por Francisco da Silveira Bueno. [Rio de Janeiro]: Ediouro, [s.d.], ISBN 85-3-070386-3.

Cancioneiro Geral de Garcia de Resende. Fixação do texto e estudo por Aida Fernanda Dias. Lisboa: Imprensa Nacional-Casa da Moeda, 1990-1993. Volumes I a IV, ISBN 972-27-0581-4.

DIAS, Aida Fernanda - Cancioneiro Geral de Garcia de Resende - A Temática. Lisboa: Imprensa Nacional - Casa da Moeda, 1998. Volume V, ISBN 972-27-0879-1.

DIAS, Aida Fernanda - Cancioneiro Geral de Garcia de Resende - Dicionário (Comum, Onomástico e Toponímico). Lisboa: Imprensa Nacional - Casa da Moeda, 2003. Volume VI, ISBN 972-27-1172-5.

LE GENTIL, Pierre - La poésie lyrique espagnole et portugaise à la fin du Moyen âge: les thèmes, les genres et les formes. 2 vol. Rennes: Plihon, 1949-52, 205100272X 9782051002721.

OSÓRIO, Jorge A - "Do Cancioneiro “ordenado e emendado" por Garcia de Resende". in Revista da Faculdade de Letras, Línguas e Literaturas. Porto. ISSN 0871-1682. V. XXII, II série, (2005), pp. 291-355.

REBELO, Luís de Sousa. “A tradição clássica na Literatura Portuguesa”. in REBELO, Luís de Sousa Movimentos. Humanismo. [s. 1.]: Livros Horizonte, [s.d.]. ISBN 972-24-0514-4, pp. 69-97.

RIBEIRO, Cristina de Almeida - "Três breves apontamentos sobre poetas do Cancioneiro Geral (Diogo Brandão, Anrique da Mota e o Doutor Francisco de Sá)". in ALMEIDA, Isabel; ROCHETA, Maria Isabel; AMADO, Teresa Amado (org.) - Estudos para Maria Idalina Resina Rodrigues, Maria Lucília Pires, Maria Vitalina Leal de Matos. Lisboa: Departamento de Literaturas Românicas da Faculdade de Letras da Universidade de Lisboa, 2007. ISBN 989-95609-0-1. pp. 171-190.

RODRIGUES, Sara - "Diálogos ibéricos en el Cancioneiro Geral". in FERNANDES, Ângela Fernandes et allii (eds.) - Diálogos Ibéricos e Iberoamericanos. Lisboa: ALEPH / Centro de Estudos Comparatistas / Academia Editorial del Hispanismo, 2010. ISBN 978-84-96915-76-3. pp. 887-899.

RODRIGUES, Sara - "Técnicas e ideología epidíctica en las alabanzas de Álvaro de Brito, poeta del Cancioneiro Geral". in BELTÁN, V. Beltrán; PAREDES, J. (eds.) - Convivio. Cancioneros peninsulares. Granada: EUG, 2010. ISBN: 978-84-33851-44-4. pp. 183-196.

ROCHA, Andrée Crabbé. Aspectos do Cancioneiro Geral. Coimbra: Coimbra Ed., [s.d]. ISBN 970529s1950. (Colecção Universitas).

\section{NOTAS}

1. Lembre-se que, para os poetas clássicos, o ideal de poesia era a conjugação entre pensamento e arte, o que será marcado na poesia de Camões, por exemplo, quando, no Neoclassicismo, escreve no seu Os Lusíadas: "Cantando espalharei por toda parte, / Se a tanto me ajudar o engenho e a arte (...)". (Estrofe 2, Canto I). Grifo meu. Para Francisco da Silveira Bueno, "distingue o Poeta entre engenho, talento inventivo, natural, dom individual de cada um, e arte, técnica, fruto de aprendizado, ao alcance de todos". É um conceito, para Camões, seiscentista, mas que não deixa de ter por base a cultura greco-romana, haja vista que, ainda segundo Bueno, "a oposição 'engenho' e 'arte' é outro latinismo muito comum. Ovídio: ‘Enim ingenio maximus, arte rudis”.

2. Recorro a Luís de Sousa Rebelo, quem comenta que a fixação da norma linguística já havia preocupado Petrarca, uma das grandes tarefas levadas a cabo pelo Humanismo; mais adiante, diz que "as primeiras polémicas dos humanistas e dos seus precursores (Dante, Petrarca, Boccaccio) foram travadas contra religiosos, que agiam mais por moto próprio do que por injunção da alta hierarquia eclesiástica". Rebelo elenca, ainda, outras personalidades mais ilustres do primeiro 
humanismo, além de Boccaccio: Luís Marsili (1330-1394), Salutati (1331-1406), Leonardo Bruni (1370-1444), Cosme de Médicis, Manuel Crisóloras, Poggio Bracciolini (1380-1459) e Ângelo Poliziano (1454-1494), este, tendo sido mestre de João Rodrigues de Sá de Meneses, um dos poetas palacianos tradutor de Ovídio.

3. Em seu estudo, referenciado na nota anterior, Luís de Sousa Rebelo relata o que foi o Humanismo em Portugal e a relação deste com a Itália, que enviava para a península, desde D. João I até D. Manuel, nos inícios de 1500, humanistas italianos, os quais colocavam os portugueses em contato com a Antiguidade clássica. Para Jorge A. Osório "o Humanismo chega a Portugal no tempo que o Cancioneiro documenta".

\section{AUTOR}

\section{GERALDO AUGUSTO FERNANDES}

Universidade Federal do Ceará, Centro de Humanidades, Departamento de Literatura Portuguesa, 60020-121, Fortaleza, Ceará, Brasil

geraldoaugust@uol.com.br 